\title{
CEREMONIA DE NOMBRAMIENTO DE PROFESOR EMÉRITO \\ (1998)
}


CITAM Derechos Reservados.

La reproducción total o parcial de este artículo se podrá hacer si el ITAM otorga la autorización previamente por escrito. 


\title{
PRESENTACIÓN
}

\author{
DESIGNACIÓN DE \\ PROFESOR EMÉRITO
}

Buenas noches, señoras y señores:

Nos encontramos reunidos hoy para un acontecimiento que llena de honor y satisfacción a la comunidad del ITAM, la distinción de Profesor Emérito al Dr. Carlos de la Isla.

Carlos de la Isla Veraza realizó estudios de Humanidades Clásicas en la Universidad de Comillas en Santander, España. Es licenciado en Filosofía por la Universidad Gregoriana de Roma, donde realizó también otros estudios. Los estudios de posgrado los realizó en la Universidad de Salamanca, España. Ha sido profesor en varias universidades en el país y en el extranjero por más de 35 años y ha participado en diversos congresos nacionales e internacionales.

Ha publicado un número considerable de artículos relacionados con temas humanos y sociales, principalmente sobre filosofía de la educación.

Actualmente es profesor numerario de tiempo completo en el Departamento Académico de Estudios Generales. 
CITAM Derechos Reservados.

La reproducción total o parcial de este artículo se podrá hacer si el ITAM otorga la autorización previamente por escrito. 


\section{RELACIÓN DEL}

PROCESO SEGUIDO

PARA LA DESIGNACIÓN

DE PROFESOR

EMÉRITO

Lic. José Ramón Benito Alzaga

\section{El Reglamento para la Designación de}

Profesores Eméritos del Instituto Tecnológico Autónomo de México dice en su artículo primero:

El Emérito es una distinción que el Instituto Tecnológico Autónomo de México otorga a miembros de su personal académico de tiempo completo, medio tiempo y asignatura, que por su dedicación y labor eminente en las actividades académicas en el Instituto, por su calidad humana, por su espíritu de servicio, se han convertido en modelo para los demás miembros del claustro académico y la comunidad universitaria en su conjunto.

En el artículo segundo dice:

Para que a un miembro de la planta docente se le otorgue la distinción de Emérito tendrá que:

$1^{\circ}$ Haber dedicado 25 años o más a funciones académicas en el Instituto y haber tenido durante ese tiempo un desempeño sobresaliente en sus labores académicas.

En el artículo cuatro reza:

Cada dos años la Junta de Coordinación Académica emitirá una convocatoria para que los miembros de tiempo completo del personal académico del Instituto, que hayan cumplido la antigüedad mínima requerida por 
el Estatuto del Personal Académico y este Reglamento, sean considerados para la designación de Profesor Emérito en el concurso correspondiente.

El artículo once expresa:

La Junta de Gobierno otorgará la distinción de Profesor Emérito sustentada en la recomendación formulada por el Comité Calificador para el otorgamiento del Emérito.

El artículo doce dispone:

El otorgamiento de la distinción de Profesor Emérito se hará público en ceremonia formal, que tendrá lugar en sesión de la Junta de Facultad a la que asistirán el Presidente de la Junta de Gobierno del Instituto, todos los Profesores Eméritos del mismo y los miembros de la Junta de Coordinación, en esa ceremonia el Presidente de la Junta de Gobierno entregará al profesor distinguido el nombramiento correspondiente.

Habiéndose cumplido con los requisitos señalados y estando hoy reunidos para tal efecto en esta sesión extraordinaria de la Junta de Facultad, señor Carlos Orozco, solicito atentamente a usted haga pública la distinción de Profesor Emérito del Instituto Tecnológico Autónomo de México al Profesor Carlos de la Isla Veraza.

\section{C.P. Carlos Orozco}

Muy buenas noches señores, buenas noches señores del estrado:

Doctor Carlos de la Isla, me es altamente grato entregar a usted en esta ocasión, en representación del presidente de la Junta de Gobierno, Lic. Alberto Baillères, este documento que lo acredita a usted como Profesor Emérito.

Muchas felicidades profesor. 


\section{DISCURSOS}

\section{Lic. José Ramón Benito Alzaga}

Cuando se quiere a una persona, resulta más difícil hablar de ella. Lo que parecería ser más fácil, se complica. Si, además del afecto, se mezclan la admiración y la gratitud, estos sentimientos agregan tintes y aspectos que vuelven todavía más atrevida la empresa. Y esto es peor si hay que hacerlo en público y en una ceremonia solemne como esta. Ni qué decir si de quien se trata es de don Carlos de la Isla, tan poco amigo de halagos y alabanzas y que apenas advierte algo que asoma en esa dirección, lo rechaza con un manifiesto gesto de disgusto antes que con cualquier palabra.

Sirva lo anterior más como explicación que como excusa. Algo, esto último, que las más elementales reglas de un discurso desaconsejan. Tal explicación me parece necesaria para obtener la indulgencia de ustedes y en especial de quien estamos celebrando. Así se entenderá el tono personal de mis comentarios. Cuando son poco menos de cuarenta años de una relación, de modalidades diversas, pero no menos significativas, no puede uno sino admitir que de la abundancia del corazón hable la boca.

Tuve la suerte de conocer a Carlos de la Isla y de que fuera mi profesor en 1961, en la Universidad Iberoamericana. Fueron unos cursos de Lógica y de Ética que impartía el joven, pero no menos brillante profesor, recientemente llegado de una larga estancia en varias universidades europeas. Su juventud y su brillantez lo hacían desde entonces admi- 
rado y buscado por sus estudiantes, especialmente por sus alumnas, a quienes, con su reciedumbre habitual, no sin sentido del humor, sosegaba advirtiéndoles que no les estaba ofreciendo su mano.

Poco tiempo después, en mis primeros años de actividades docentes, tuvo a bien llamarme a colaborar con él en el Colegio Vallarta, de cuya preparatoria era director.

Fue en 1971 cuando empezó a dar clases en el ITAM, que en aquel entonces estaba en Marina Nacional. Aceptó amablemente mi invitación a venir a esta institución, a la cual me pareció que desde el primer momento empezó a querer y en donde fue sintiéndose cada vez más como en su casa. Yo no tenía la menor duda de que así habría de ser, y apenas tuve la responsabilidad de pensar en profesores como los que el ITAM requería, el nombre de Carlos de la Isla estaba al comienzo de la lista.

Poco a poco, y no sin cautela — pues significaba dejar serios compromisos adquiridos hacía algunos años-, aceptó incorporarse más; primero de medio tiempo y solo poco después de tiempo completo. Así encontró el maestro De la Isla un espacio universitario con el que se identificó plenamente y el ITAM se enriqueció con uno de sus grandes profesores. Quisiera, sencillamente, apuntar tres aspectos de su personalidad que me parecen sumamente apreciables y que quienes han tenido el beneficio de su trato, podrán seguramente reconocer. Caballero. Humanista. Pedagogo. Aunque mucho de quijotesco hay en don Carlos, no es un caballero que combata contra molinos de viento ni que confunda a una mujerzuela con una dama.

Ciertamente, es un hombre de grandes ideales, pero con los pies bien plantados en la tierra, en una tierra a la que ama intensamente. Sin sueños que resulten de la fiebre o de los humores, está dispuesto a luchar sin tregua por causas bien identificadas y que ameriten jugarse la vida: se halla equipado con las armas de la razón y la elocuencia, y con una voluntad y un valor a toda prueba.

Personalidad recia, la caballerosidad de Carlos de la Isla es respetuosa, siempre dentro de las buenas maneras. Cuando es necesario, se expresa con coraje, como él mismo lo dice, pero con gran dignidad. En la forma y en el fondo, hay en su actuación un talante aristócrata que, 
sin embargo, sabe acoger a quien no lo tiene, sin por eso ser tolerante con ninguna bajeza. Hay en él una solemnidad muy propia y envuelve a quien se la acerca, sin ahuyentarlo. Su sentido del honor y su honestidad lo distinguen siempre. Fino, cortés a la vez que firme, su trato es directo y, antes que actuar con tibieza, prefiere alejarse. El esmero que pone en todo, el escrupuloso cumplimiento con que realiza aquello a lo que se compromete, permiten tener la seguridad del éxito de sus empresas.

Su humanismo es un humanismo vibrante, no acartonado ni de una erudición chocante y estéril. Gran conocedor de los clásicos griegos y latinos, con un dominio de sus propias lenguas, sabe encontrar en ellos lo que de eterno hay en el hombre y aprovechar la enseñanza que nos ofrecen para comunicar a las nuevas generaciones su vasta riqueza.

En él, la filosofía, las ciencias humanas y las ciencias sociales tienen como centro de interés comprender mejor la vida de los seres humanos $\mathrm{y}$ hacer de estos personas cabales.

La frase de Terencio, "Soy hombre y nada humano me es ajeno", una de las que mejor expresan el auténtico humanismo, resuena en Carlos de la Isla con peculiar intensidad y motiva su interés intelectual.

Cuando conoció los planes de estudios del ITAM y los objetivos del Instituto, mostró gran interés. Vio en los cursos de Estudios Generales una forma particularmente adecuada para contribuir al logro de esos objetivos y la manera de realizar en el presente una obra de humanismo.

En nuestro mundo convulsionado, tan lastimado y a la vez lleno de posibilidades y bondades; en el presente y en el futuro de un México tan demandante y tan herido por las intolerables injusticias y desigualdades, a la vez que tan noble y grande, tanto el verdadero académico como el auténtico profesionista no podrá serlo si se desentiende de esas realidades. Para ello requiere ante todo un profundo conocimiento del hombre, del hombre que no es solo sus circunstancias, pero que sin ellas no existe. Conocimiento comprometido del hombre, crítico y con un profundo sentido de responsabilidad son cualidades que requieren los que habrán de conformar la sociedad de una nueva era. La formación de estas personas debe ser la aspiración y la tarea de la universidad y del verdadero humanista. 
El humanismo no es un sentimentalismo, sino razón impregnada de un sentimiento al que dirige y en el que se inspira: es conocimiento y realización del hombre integral.

Si los objetivos del ITAM pretenden dar a sus estudiantes una formación humanista integral, humanistas como Carlos de la Isla tienen muy claro lo que eso significa y cómo hay que lograrlo.

Hoy se ha puesto de moda entender la función del maestro como una labor de acompañamiento. Me parece que más por razones de carácter psíquico y social que por un afán filológico, se está recuperando el sentido de la palabra "pedagogo". El profesor De la Isla es un entusiasta convencido de ese sentido.

Su pedagogía es una pedagogía de la concientización y de la liberación, que se sitúa desde la persona del estudiante, el cual, por serlo, está potenciando su condición humana de ser que busca la verdad, una verdad que por necesidad habrá de apelar a su vocación esencial de ser en búsqueda del bien.

La verdad que no libera no es verdad sino ideología. Por verdadero que sea un enunciado, como verdad expresada y comunicada, si no contribuye al alumbramiento del espíritu de quien la expresa y de aquel a quien se comunica, es manipulación y sometimiento.

Por eso no puede haber verdad sin conciencia, verdad sin autoposesión de quien es poseído por ella, verdad sin liberación.

¿Qué misión podría considerar como más propia y con la cual mejor podría identificarse un pedagogo, sino la de una institución que se propone contribuir a la formación integral de la persona y al desarrollo de una sociedad más libre... y más justa? Porque la libertad sin justicia es una afrenta y una burla. La libertad que se consigue a costa del sometimiento es una ilusión y una gran mentira. El reconocimiento y el señorío obtenidos por la violencia no son sino formas más penosas de sumisión y de enajenación. Ya Hegel lo vio genialmente en su dialéctica del amo y del esclavo.

Verdad, reconocimiento, libertad y justicia han de conducir al educando a un auténtico sentido de responsabilidad y, por ello, el educador ha de acompañar al educando al logro de su autoconocimiento, ape- 
lando al sentido de la dignidad y de los derechos fundamentales de la persona humana. Autoconocimiento que abre y remite al conocimiento del mundo y de los demás. Autoconocimiento que no puede alcanzarse sin el desarrollo de un genuino sentido crítico. Una crítica que conlleva el reclamo al compromiso y a la actuación solidaria. Porque un autoconocimiento crítico no puede ser encapsulamiento individualista, monadológico, en términos de Leibniz, sino apertura y exigencia de respuesta y actuación responsables. Es decir, sin la realización de la justicia, solidaridad y responsabilidad son palabras vacías, cuando no agravios imperdonables.

En la definición de principios de nuestro Instituto se manifiesta una filosofía educativa que entiende "al ser humano como ser libre, como ser social, comprometido en la elevación y el progreso humano y como ser llamado por vocación esencial a buscar la verdad y el bien".

Por ello, esta filosofía considera que "toda educación debe tender a mejorar al ser humano mediante el enriquecimiento de sus mejores valores, la integración de su persona, la formación de su conciencia y el acrecentamiento de su capacidad de servicio".

Cuando un profesor decide formar parte del claustro del ITAM, no puede ignorar lo que define a la institución a la que ingresa y lo que ella le exige, y tampoco puede orientar su acción según criterios contrarios - o al menos ajenos - sin traicionarse a sí mismo y a la institución que lo acoge.

La pedagogía de Carlos de la Isla ha encontrado en la filosofía educativa del ITAM una magnífica expresión con la que ha podido identificarse y a la que ha contribuido a hacer realidad de manera original y a la vez compartida e institucional.

Cuando un profesor encarna en sus convicciones y en su acción, de una manera ejemplar, los principios y valores que inspiran a su institución, alcanza un lugar eminente. Esto significa ser Profesor Emérito en el ITAM. 


\section{Dr. Arturo Fernández}

Es un privilegio poder participar en esta ceremonia de distinción del doctor Carlos de la Isla como Profesor Emérito del Instituto, desde una doble posición: como su exalumno y como Rector del ITAM.

Tuve la fortuna de ser su alumno en el curso de Problemas de la Civilización Contemporánea durante mi primer semestre en el ITAM, en septiembre de 1972. Desde el primer día quedé profundamente impresionado por su recia personalidad y su vasta cultura, por su enhiesta figura, su impecable peinado y vestido, sus recias facciones que contrastan con una mirada dulce y penetrante, su temperamento flemáticamente anglosajón, casi victoriano. Todo ello, aunado a su impecable retórica, con sentencias expresadas en oraciones cortas y fulminantes, ricas en citas, producto de constantes reflexiones, me hizo preguntarme, una y otra vez, sobre el origen de tan distinguido profesor. ¿Se trataría de la reencarnación de un hombre de la Antigüedad, de la Edad Media o del Renacimiento? ¿O era un hombre de nuestro tiempo? Como hombre de la Antigüedad, habría sido educado intelectualmente en la Grecia antigua por maestros como Platón y Aristóteles, pero forjado física y moralmente en Esparta. Si se tratara de un hombre de la Edad Media, probablemente habría sido un monje escolástico, discípulo de Tomás de Aquino, pero, a la vez, un caballero armado de las Cruzadas. Por su espíritu crítico, también podría tratarse de un hombre del Renacimiento. Sin embargo, me sentí confuso con todas estas especulaciones, ya que, al mismo tiempo, su conocimiento, preocupación y pasión por el presente y futuro de la civilización contemporánea me sugerían que se trataba de un hombre de nuestro tiempo.

Finalmente, comprendí que el doctor Carlos de la Isla, como todos aquellos hombres con una formación clásica en las humanidades que asumen una responsabilidad y compromiso con la humanidad en cuanto al destino de la civilización, son, en realidad, hombres de todos los tiempos. Son herederos de la civilización occidental y asumen la responsabilidad por su destino. El doctor De la Isla es, en ese sentido, un hombre de todos los tiempos.

Su pasión por el destino de la civilización, por la justicia y la libertad es manifiesta y contundente en cada sesión de clase. Su vehemencia en 
contra de la deshumanización de la civilización moderna y sus consecuencias es memorable. Su figura erguida, su impecable arreglo y su fino tacto como manifestación de su lenguaje corporal nos transmitían valores como la rectitud, la honradez y la compasión. Bien decía Aristóteles que los modales son el espejo del alma.

Como exalumno, doctor De la Isla, guardo de usted los más gratos recuerdos y, sobre todo, sus enseñanzas explícitas e implícitas y un gran cariño y afecto. Como Rector, me siento complacido de que usted forme parte de nuestra facultad.

Para nuestra institución es un orgullo que con su generosa y brillante labor en el aula, en su cubículo, en los seminarios y conferencias contribuya a transmitir sus conocimientos, a compartir sus reflexiones y, sobre todo, a guiar con su mayéutica mano el despertar intelectual de nuestros jóvenes estudiantes en el camino para adquirir un pensamiento propio y una conciencia de su responsabilidad en la conducción de su propia vida y en la de su actividad profesional y ciudadana.

Como parte del triunvirato de Estudios Generales en aquel año escolar 1972/73, con José Ramón Benito y Ramón Zorrilla, que en paz descanse, contribuyó a configurar una parte importante de la filosofía educativa y de los objetivos institucionales del ITAM.

El énfasis en los aspectos formativos e integrales de la educación que se imparte en nuestro Instituto es claramente un triunfo y un acierto de ustedes.

Por su vocación genuina y protagónica de educar a los jóvenes, por su espíritu crítico y por ser un estudioso incansable, un hombre reflexivo y preocupado por el presente y por el futuro del país y de la humanidad, el doctor Carlos de la Isla es, sin duda, un modelo que debe inspirar a nuestra joven facultad.

Con sus modales y con su sobriedad, también nos ha enseñado que la influencia y el ejemplo son parte de la responsabilidad formativa del verdadero maestro.

Al doctor Carlos de la Isla le auguramos una influencia inmortal de esfuerzo formativo, en el mismo sentido en que Henry Adams se refiere a los verdaderos maestros, como aquellos "que inciden hasta la eternidad y nunca pueden percibir hasta dónde llegará su influencia”. En efecto, un 
hombre o mujer bien educado y formado desparrama sus acciones sobre sus descendientes y sus allegados.

Para el ITAM es un honor y una obligación moral conceder esta distinción al doctor De la Isla. Para él, un muy merecido y bien ganado reconocimiento. Gracias.

\section{Lic. Javier Beristain Iturbide}

Estamos de fiesta en el Instituto Tecnológico Autónomo de México. La designación de un Profesor Emérito hecha por la Junta de Gobierno tomando en cuenta las recomendaciones de la comunidad académica, es uno de los grandes motivos de celebración en nuestra casa de estudios. En un profesor emérito se reúnen la estabilidad y continuidad del programa universitario con los merecimientos personales. Al perdurar y prosperar, la casa de estudios proporciona el ambiente que facilita el despliegue de los conocimientos y aptitudes de sus maestros, quienes son, por mucho, su más valiosa riqueza.

Este día festejamos a Carlos de la Isla, profesor sin igual del Departamento de Estudios Generales del ITAM, quien se une a un grupo de maestros que han dado su vida a la educación universitaria en esta nuestra casa de estudios, nuestra casa del estudiante. Los cursos y las enseñanzas de Carlos de la Isla han marcado para siempre a miles de alumnos del ITAM; asimismo, su calidad humana y profesional es admirada por ellos y sus colegas de la Facultad. Hablar de Carlos de la Isla es hablar de lo mejor que tienen nuestro Instituto y la educación universitaria de México.

Las contribuciones de don Carlos al ITAM son ricas y variadas. Maestro y educador, amigable caballero coordinador de las reuniones de la Facultad, conciencia que recuerda y preserva los mejores valores del ITAM, crítico implacable de la sinrazón, la intolerancia, el dogmatismo, la demagogia y el fanatismo, partidario apasionado de la sociedad abierta, las libertades, la justicia, la democracia y la dignidad del hombre.

Carlos de la Isla llega al ITAM en el momento apropiado. Los aires de reforma universitaria habían entrado a nuestra casa. En la década 
de 1960 sesenta nació el nuevo ITAM, y se trazó misión, estrategia y planes: formar hombres y mujeres para llevar a cabo el cambio, contribuir a un México más libre y más justo son la esencia de la propuesta y del compromiso. Había que replantear las carreras y asegurar que la formación integral precediera a la especializada. Antes que contador o licenciado había que ser hombre. Había que resistir las prisas de los mismos alumnos, quienes querían ser profesionales sin haber vivido la experiencia universitaria.

Descubrimos en Ortega y Gasset las pistas hacia la formación universitaria: "La universidad consiste, primero y por lo pronto, en la enseñanza superior que debe recibir el hombre medio [...] al que hay que hacer, ante todo, un hombre culto, situarlo a la altura de los tiempos [...] y un buen profesional". Más adelante, Ortega afirma que quienes toman las decisiones en las sociedades son, precisamente, los profesionales; así pues, resulta fundamental que, "aparte de su especial profesión, sean capaces de vivir e influir vitalmente según la altura de sus tiempos. Por eso es ineludible crear de nuevo en la Universidad la enseñanza de la cultura o sistema de ideas vivas que el tiempo posee..."

Estudios Generales es la gran idea del ITAM para aterrizar las recomendaciones de Ortega. El ITAM pudo haber avanzado sin Estudios Generales, pero ahora estaríamos en una institución diferente, en el remoto caso de estar aquí. Gracias a Estudios Generales cambiaron métodos y contenidos, se formó un núcleo insustituible de profesores de planta, se impartió a todos un conjunto de destrezas y conocimientos, se despertaron y encauzaron inquietudes, se distinguió el ITAM de sus competidores y se dio un paso gigantesco hacia la excelencia.

Si bien es cierto que no todo se debe a Estudios Generales, esta División Académica ha sido — que no quede duda - la característica que separa y distingue al ITAM de las instituciones de educación superior de nuestro país.

No podemos hablar de Estudios Generales sin pensar en sus maestros. Es más, Estudios Generales es su grupo de profesores. Y dentro de ese grupo Carlos de la Isla brilla con intensidad. De él emanan las luces de la sabiduría, del humanismo, de la universalidad del conocimiento: de la universidad.

Es tiempo de recordar la visión universitaria de Carlos de la Isla, cuya síntesis se expresa en: "la universidad que se piensa a sí misma 
[...] ha de ser verdaderamente autónoma: con entera independencia y libertad; sin compromisos con corrientes políticas, económicas o doctrinales; empeñada solo en el logro de sus propios objetivos; libre para denunciar y anunciar". Se trata de la universidad de la universidad - o de la universidad dentro de la universidad — que actúa como la conciencia crítica de la conciencia social.

Mientras De la Isla esté aquí, el ITAM seguirá siendo la casa del estudiante, seguirá luchando contra los dogmas y la cerrazón, seguirá impulsando los valores universales y seguirá empeñado en contribuir a que México sea más libre y más justo.

Gracias, don Carlos, por su amistad, su caballerosidad, su honradez, su pasión; gracias por sus enseñanzas; gracias por ser la conciencia crítica; gracias por ser la universidad dentro del ITAM.

\section{Dr. José de Jesús Barba Martín}

Señor don Carlos Orozco, miembro de la Junta de Gobierno, en representación del señor don Alberto Baillères, presidente de la Junta de Gobierno del Instituto Tecnológico Autónomo de México;

Señor Rector, Dr. Arturo Fernández;

Señor Decano, Mtro. José Ramón Benito, Director de la División Académica de Estudios Generales y Estudios Internacionales;

Señores miembros de la Junta de Gobierno, de la Junta de Coordinación y miembros de la Facultad;

Querida Catherine y queridos miembros de la familia De la Isla;

Estudiantes, señoras y señores:

A petición, honrosa, del maestro José Ramón Benito, Director de la División de Estudios Generales y Estudios Internacionales del Instituto, tomo muy gustosamente la palabra en este homenaje al doctor Carlos de la Isla Veraza.

A lo largo de la historia, instituciones de diversa índole desarrollan su propias cuasiliturgias y tradiciones. Desde muy antiguo es costumbre rendir honor y gratitud a los hombres que han contribuido al descubrimiento, a la profundización y a la expansión de los bienes culturales o de cualquier índole. Menos frecuente es el reconocimiento en vida a 
esos que un día Romain Rolland llamó, no sin cierto sabor positivista, "les saints de nôtre calendrier": esas mismas personas que con su presencia ejemplar y con sus aportaciones, no por cotidianas menos considerables y auténticas, constituyen un acicate ampliamente espiritual, moral y cívico para quienes con ellos conviven, trabajan y tratan de construir - de manera honesta y digna - un mundo mejor. Todo reconocimiento justo y oportuno a la virtud intelectual o moral de los miembros de un grupo, cualquiera que este sea, lo fortalece y lo acrecienta con mediciones que van más allá de las ciencias de lo preciso. Es, pues, sabio de nuestras autoridades rendir honor a esta tradición que, así respetada, nos dignifica a todos.

Sin embargo, dado que todas las relaciones que entablamos en nuestra vida necesariamente entrañan un aspecto humano, y que mi trayectoria académica comparte afinidades con el motivo de la celebración, se me pidió hablar en esta ocasión. Me unen, en efecto, al doctor De la Isla 45 años de amistad intelectual y personal, de ideales comunes y de una prolongada, justa y nunca desilusionada admiración hacia él de mi parte. Puedo decir más: oí hablar de él y lo admiré por su merecida fama de líder joven y ejemplarmente exigente con él mismo, aun antes de conocerlo personalmente al principio de mi adolescencia. Fue desde entonces, para mí y para muchos otros, un hermano mayor digno de emularse.

Casi apenas terminada la Segunda Guerra Mundial, en 1946, a través de un Atlántico todavía sembrado de minas, llegó, muy joven todavía, en el barco Marqués de Comillas a Santander, en Cantabria, pleno de ilusiones. Su madre y su padre, el ingeniero queretano, don Agustín de la Isla (hijo del leal gobernador porfiriano don Adolfo de la Isla), lo despidió recordándole el compromiso de mantener siempre la dignidad y el sentido de responsabilidad característicos de su familia. Fue como cuando a Aquiles lo mandó su progenitor a la guerra de Troya recomendándole: aiéi aristéuein, "sé siempre el mejor". Y de tal manera hizo suyos el joven De la Isla ese deseo y tal admonición paternos que entre nosotros, sus jóvenes compañeros, en un grupo ya considerado selecto, decir u oír decir "hermanos De la Isla" era significar o entender un sinónimo de excelencia. 
Las privaciones de la posguerra, la escasez, la obligatoria cartilla de racionamiento alimentario, el difícil clima y la inquietante belleza de los paisajes de la cornisa cantábrica, no menguaron su entusiasmo por su formación personal humana e intelectual. Brillaba entonces la Universidad de Comillas, por sus lúcidos programas de Humanidades Clásicas. Ofrecía a los escolares de todo el ámbito de habla hispana el mejor claustro académico en esa área de estudios. Profesores especializados en Oxford, Lovaina, Roma y Salamanca fueron sus maestros: Francisco Javier Baeza, Domingo Mayor, Enrique Basave, Eusebio Hernández, Luis Penagos, Luis Alonso Schoekel... En ese entorno universitario de hermosos, aunque sobrios, edificios de ladrillo rojo flanqueados de arces, que tenía en lo alto, en el frontero alcor, el admirable palacio neogótico de Sobrellano, adyacente al "capricho" arquitectónico de Gaudí, y, junto a los embatidos acantilados, un mar grisáceo cuya sola visión, austera las más de las veces, era por sí misma educadora de espíritus reflexivos, Carlos de la Isla fue forjando al mismo tiempo su carácter y su idea del hombre. Frente a sí tenía a una Europa sometida al comunismo total $y$, por otra, un continente que se hallaba en penosa reconstrucción posbélica.

Viajes tempranos a Francia le abrieron los ojos a nuevas modalidades de pensamiento: entonces la existencialista, una de las cuatro corrientes filosóficas que - junto con la liberal, la marxista y la posmoderna - le ha tocado conocer y vivir. Era difícil que su tradición familiar de participación cívica, los diversos entornos geográficos vividos, así como la exposición personal a las contrapuestas ideas políticas y filosóficas de su experiencia de aquellos años, no hubiesen de fraguar en Carlos de la Isla una personalidad netamente filosófica y de una voluntad desde entonces claramente comprometida con su preocupación social.

Un paso decisivo en su formación fue su ingreso en la Pontificia Universidad Gregoriana, considerada en Norteamérica como la PrincetonHarvard-Yale de la Iglesia Católica. El remansado otoño romano de 1950 encontró ya al joven De la Isla frecuentando la Piazza della Pilota, desde 1930 sede de la universidad que con el nombre, entonces, de Collegio Romano había fundado en 1581 el Papa Gregorio XIII. Corrían 
los años de la década de 1950, finales del neorrealismo en la literatura y en la cinematografía italianas que abrevaban en esa misma realidad que el joven Carlos veía con los ojos ávidos y avizores de quien siente en su propia vida una gran responsabilidad. Fue afortunado de contar durante ese periodo universitario con el favor y la atención de personalidades académicas de primera línea en la filosofía, en la historia del arte, en la crítica de la ciencia, en la sociología y en otras áreas del conocimiento: los jesuitas don Paolo Dezza (rector magnífico), Vittorio Marcozzi, el padre Francesco Morandini (amigo personal del filósofo), Jacques Maritain (quien sentía aprecio por el joven Carlos), el padre Engelbert Kirschbaum, el padre Nowlan de Harvard, Joseph de Finance, Nicolás Caminero y el excomunista austríaco, padre Gustav A. Wetter, cuyos libros explicativos del pensamiento marxista gozaban de tal prestigio que en el mismísimo Instituto de Estudios Soviéticos de Moscú se empleaban sus textos (habida cuenta, claro está, de excluir de ellos la parte refutativa). Estudiaron en la prestigiosa institución, al mismo tiempo que él, personalidades ahora tan señeras como la del cardenal Joseph Ratzinger y tan resistentes a la imposición sin discusión como la de Hans Kühn; autores liberales como Michael Novak, asesores presidenciales, profundos escrituristas bíblicos, eminentes rectores de universidades católicas, famosos conductores sociales, brillantes críticos, connotados expositores, grandes profesores.

Era la Roma de aquel entonces una mezcla de conservadurismo y de inquietud de apertura, de concentración en el estudio y de conciencia de los tiempos: cada paseo cultural o de descanso era un entorno de gloriosa soledad circundada por témpanos de historia... La Gran Ciudad, en la que la piqueta de Cronos había cavado tantos siglos:

... torre, columna o cruz, la piedra fría

escarchada de luces y reflejos,

los arquitrabes viejos,

y junto al cielo la campanería...

La Roma silenciosa y milenaria, roca de fe y faro de dulzura; 
que sabe ser espada firme y dura,

ceñirse la armadura,

o buscar en el cielo una plegaria...

como rezaban los versos de un precoz poeta de nuestro grupo.

Era la Roma de un papa todo blanco con los brazos frecuentemente extendidos sobre un balcón, de multitudinarias peregrinaciones políglotas; la Roma vistosa de los carabinieri, de los soldados de las bases de Livorno y de los marinos de la Séptima Flota en asueto, de las rubias turistas norteamericanas en autos descapotables, de amplios vestidos floreados, pañoletas al pelo y anguladas gafas de sol, de las inevitables y ruidosas Vespas y Lambrettas; la Roma de los frecuentes monseñores y parsimoniosos purpurados, de los ubicuos estudiantes internacionales con sotanas de colores: las negras, las azules, las rojas, las sobrias y las decoradas con listones de uniformes cuasimilitares como las de los de Propaganda Fide, las de color de vino, como las de los miembros del Collegium Germanicum-Hungaricum, para distinguirlos si bebían inmoderadamente la birra o cerveza, ya desde los lejanos tiempos que menciona el historiador Ludwig von Pastor en la Historia de los papas durante el Renacimiento... Era la cittá inquieta con las voces nuevas de la chiquillería callejera, de las trattorie abiertas en plazoletas casi íntimas de tan pequeñas, la urbe luminosa de las mil fuentes blancas, sonoras, seculares... la ciudad del Gianicolo con los copudos árboles emblemáticos y con los musicales pájaros que Ottorino Respighi nos recuerda en su poema sinfónico "I Pini di Roma".

Era también, para la experiencia histórica del joven de avanzados estudios, la Roma inmediata a los comicios ante el peligroso crecimiento del comunismo; la Roma en la que, por orden papal, tañeron al unísono las campanas eclesiales día 6 de octubre de 1956, durante los despiadados bombardeos rusos sobre Budapest y, luego, ante los conflictos internacionales por el canal de Suez. En este mundo de admiración por la Antigüedad, de reposada reflexión filosófica, de vida ascética $\mathrm{y}$, al mismo tiempo, de un moderado afecto por los razonables goces superiores de la vida, en un entorno casi siempre soleado, fue redondeándose la formación humana y consolidándose la forja del carácter 
y la modelación intelectual de Carlos de la Isla. Añadíase a todo ello la oportunidad de una visión internacionalista hacia el mundo actual también con una retrospectiva profunda, como querían los antiguos: memoria praeteritorum, futurorumque prudentia ("un recuerdo del pasado que garantizara una sagaz visión del porvenir") y desde un punto de mira privilegiado, en tiempos de laboratorio histórico, en una Europa de grandes líderes: Pío XII, Alcide de Gasperi, Charles de Gaulle, Winston Churchill, Konrad Adenauer y, para bien o para mal, Francisco Franco, Joseph Stalin y Joseph Broz Tito, con la vecina presencia de Abdel Nasser y de los líderes que iban surgiendo en aquel mundo cambiante.

La concentración del posgrado en la venerable Universidad Pontificia de Salamanca, cerca de los bancos escolares que ocupó en su tiempo nuestro fray Luis de León, ahondó en Carlos de la Isla el sentido de la tradición hispánica en los estudios humanístico-religiosos, junto a las piedras doradas de la famosa ciudad universitaria donde, siglos antes, el cardenal don Alonso de Fonseca había dicho a visitantes extranjeros que allí se especializaban los estudiantes en "el arte de saber acertar", ante la ascética llanura circundante que formó el alma extrañamente mística, lúcida y rebelde de Miguel de Unamuno, transcurrieron también unos años de estudio y de meditación (de varios modos espiritual), de Carlos de la Isla.

¿Es más fácil así comprender la reciedumbre del carácter personal e intelectual, la conciencia histórica y social, la profundidad, la firmeza y la verticalidad éticas que Carlos de la Isla manifiesta en sus cursos, en sus conferencias, en sus charlas con los colegas y en sus artículos, que comprueban impresos en las revistas que la buena escritura no es sino la sombra de la buena conversación?

Veinticinco años de servicio grandemente meritorio en una institución son, en el caso del doctor De la Isla, la inversión y la dedicación de lo más granado y mejor de una vida: la consagración a una profesión, la religio grammatici, como quería el humanista oxoniense Gilbert Murray, primer presidente de la Sociedad de Naciones, el testimonio de una fe académica, el encuentro comprometido de un hombre excelente con 
una universidad de excelencia que cree en ellos y se abre a los mejores para seguir favoreciendo la formación de hombres que contesten con responsabilidad a las necesidades de los tiempos de nuestro país y del mundo, con una conciencia de perfección y de justicia social declarada y abierta a todos los talentos prometedores verdaderamente interesados en entregarse, como quería el Sócrates de la cueva platónica, con una conversión total a la prédica de valores perennes y salvadores, a sabiendas de los riesgos que a veces entraña decir la verdad, pues rara vez se quiere escuchar la verdad necesaria a tiempo.

Me congratulo, pues, entusiastamente con el doctor Carlos de la Isla, lo felicito y le agradezco su ejemplo que siempre me ha acompañado. Felicito igualmente con amistad cordial a la señora Catherine Corry de De la Isla, a su hija Cathie y a sus hijos Carlos, Frank, David y Eddie. Felicito al Instituto Tecnológico Autónomo de México en la personalidad colectiva que todos en él formamos, especialmente representada en las figuras de nuestro Rector, el doctor Arturo Fernández, y de nuestro Decano, el maestro José Ramón Benito, por el acertado reconocimiento de Profesor Emérito otorgado tan justamente a nuestro benemérito colega y, para mí siempre próximo, siempre ejemplar, siempre entrañable amigo.

Muchas gracias.

\section{Dr. Carlos J. Mc Cadden M.}

Es para mí un gusto estar con ustedes festejando al doctor Carlos de la Isla. Yo lo conocí en agosto de 1974 cuando, inscrito en la carrera de Administración de Empresas, asistí a sus clases. La primera sensación que tuve fue de sorpresa; no sé exactamente cómo expresarlo. Mi idea fue: "Quién paga esto". La inmensa cantidad de capital humano que desbordaba en las clases me parecía tan extraordinaria, que la colegiatura que yo pagaba no podía ser de ninguna manera una retribución a lo que estaba yo recibiendo. 
Descubrí en las clases la nobleza de la profesión del profesor. Escuchaba yo términos rarísimos como "enajenación”, “alienación”, "antropología", temas que de alguna manera yo me había cuestionado y sin embargo me resultaban difíciles de imaginar en clase y, pese a ello, eran muy míos.

Tomé con él Problemas de la Ciencia y la Teoría I y II, e Ideas e Instituciones Políticas y Sociales III. En ese entonces descubrí mi vocación como filósofo $\mathrm{y}$, sin darme cuenta, aprendí a ser profesor; además de esos cursos con él, me impartió clases de latín, de griego y de oratoria. También me dio clases en su cubículo, clases que fueron más de humanidad que de humanidades. Con él aprendí la disciplina de dos clases a la semana y del ejercicio de la memoria. Fueron tan exitosos estos cursos de latín que llegué a sorprender a mis profesores en Suiza, cuando presenté mi examen. Fue también sinodal en mi examen profesional de Ciencias Sociales y, al final, me dijo que estaba yo licenciado para seguir estudiando, lo cual, por cierto, hice. También fui su colega a partir de 1982 cuando empecé a impartir clases. Con él aprendí a preparar clases, a estructurar y a escoger textos: aprendí todo lo relativo a la academia en esta universidad. La universidad, según me enseñó, es una vida comprometida con la sociedad, y me llamó mucho la atención que sea justamente en octubre de 1998, cuando se recuerda el acontecimiento de 1968, que se le festeje como Profesor Emérito.

Cuando fue Jefe del Departamento de Estudios Generales, lo conocí en otra faceta: fue mi jefe y lo vi desarrollarse en la vida burocrática universitaria. Aquí los asuntos eran otros: juntas, asuntos académicos de los profesores, impresión de libros, calificaciones, asistencias, etcétera.

Por último, creo poder repetir lo que dijo Aristóteles acerca de Platón: "Soy amigo de Platón, pero más amigo de la verdad", "Soy amigo de Carlos de la Isla, pero más amigo de la verdad". Sé que esto no le molesta; al contrario. El maestro Carlos de la Isla está consciente de que siempre fue maestro de maestros. Me educó con independencia de criterios: en, y para, la libertad.

Muchas gracias. 


\section{Dr. Gonzalo Hernández Licona}

Quienes hemos escogido la carrera de maestro, o los que alguna vez fuimos profesores en algún periodo de nuestra vida, nos damos cuenta de que el dilema personal más importante al que hacemos frente no es tanto, por ejemplo, la relativa falta de prestigio de la docencia en países como México: “Oiga profe — pregunta el alumno—, y usted, además de dar clases, ¿qué hace?” "Oiga profe — pregunta otro-, y usted, ¿en dónde trabaja?" "En el ITAM." "No, pero ¿en dónde trabaja en serio?" Posiblemente el principal problema de la docencia tampoco sea la tradicional baja remuneración del magisterio en nuestro país (aunque, ciertamente, vayan de la mano).

Creo que los maestros tenemos frente a nosotros un problema y un reto más importante: cómo medir realmente el alcance de nuestro trabajo, cómo saber si las horas que pasamos frente a los alumnos tendrán alguna repercusión real más allá del salón de clases; en suma, cómo saber si nuestro trabajo realmente trasciende.

El médico, por ejemplo, imprime casi literalmente una huella en sus pacientes. El buen médico rescata vidas, cura enfermedades. El arquitecto, el artista, el ingeniero, el poeta, el cineasta elaboran de la nada edificios, sinfonías, casas, esculturas, poemas y pinturas. La huella que ellos dejan en sus obras es indeleble.

Los maestros, sin embargo, utilizamos una materia prima por demás sui generis, que no permite el mismo tratamiento. Los maestros difícilmente podemos observar si nuestra obra trasciende. ¿Cómo podemos medir, entonces, nuestra contribución?

Si quisiéramos medir la calidad y por tanto la trascendencia del maestro en términos cuantitativos, tomando para ello por ejemplo la cantidad de alumnos que han pasado por nuestras aulas, tendríamos un problema fundamental. No podríamos distinguir fácilmente si el número de alumnos depende del maestro o de la institución. Una universidad grande o buena o de moda puede tener un gran alumnado y, por tanto, los maestros de esa institución tendrán también muchos estudiantes. No podemos afirmar simplistamente que ello hable bien o mal de un maestro en particular. 
Si abordamos el aspecto cualitativo no resolvemos el problema. Si quisiéramos medir la calidad del maestro por la calidad y el desempeño del alumno, tampoco quedaría claro cuál es exactamente la aportación del primero. Hay alumnos de extraordinaria calidad y con grandes logros profesionales que posiblemente nunca se hayan topado con maestros universitarios realmente buenos. El desempeño del alumno, por tanto, no constituye un criterio infalible para apreciar la calidad de sus profesores.

La pregunta persiste: ¿cómo saber si el trabajo del maestro realmente aporta algo de manera sustancial y permanente? ¿Cómo distinguir un maestro bueno de uno excepcional? En vez de recurrir a argumentos teóricos, la respuesta más directa tal vez sea tomar el ejemplo de un maestro en particular. Cada uno de nosotros tiene su propio prototipo de maestro. Para mí, y no únicamente hoy, ni solo este año ni solamente en ocasión de esta ceremonia, el modelo del maestro fuera de serie es, sin que me quede la menor duda, el maestro Carlos de la Isla.

En las clases del profesor De la Isla, el mundo de las ideas y de los problemas sociales se transformaba frente a nosotros de una manera nunca antes experimentada. La importancia de la clase no se reducía simplemente al aprendizaje de los textos, sino que era requisito indispensable debatir, analizar, criticar, volver a expresar a los autores con nuestras propias palabras. En las clases del maestro De la Isla la reflexión era más importante que la instrucción, el análisis más importante que el aprendizaje y el concepto de transformar se prefería al de entender.

Todo ello era posible hacerlo con alumnos jóvenes de los primeros semestres, tanto por la capacidad docente del doctor De la Isla como por el entusiasmo contagioso con el cual dirigía las clases. Una clase con él nunca pasó inadvertida: el debate hacía levantar pasiones; el mundo nuevo que descubríamos en cada tema abría nuestros ojos y la reflexión resultante se extendía más allá del salón de clases. Para nuestra generación, las clases del maestro De la Isla fueron la cara humana de la carrera.

Muchos de nosotros no hemos olvidado las reflexiones surgidas de esos cursos, aunque a veces quisiéramos que así sucediera. En dichas clases descubrimos y reforzamos el hecho de que este mundo, y espe- 
cialmente este país, es bastante imperfecto y bastante injusto. Si bien el concepto de injusticia puede ser diferente para cada persona y está sujeto a debate, nos quedaba muy claro que si en México el 10\% más pobre de la población obtiene solo el $1.6 \%$ del ingreso total, mientras que el 10\% más rico obtiene el $38.4 \%$ del ingreso total, la injusticia (de cualquier manera que la midamos) es enorme. Y esto se confirma en muchas otras instancias de la vida nacional: desde la impartición de justicia hasta el trato desigual al que quedamos sometidos cuando ocurren los desastres naturales.

Esas reflexiones nunca se olvidan.

El maestro De la Isla insistía permanentemente en otro concepto relacionado con el anterior: si bien la educación tiene como uno de sus objetivos principales entender el mundo, lo que también podemos y debemos hacer es transformarlo. Saber que el mundo es imperfecto despierta una respuesta lógica: hay que cambiarlo. El estudiante que entiende bien el funcionamiento de la sociedad es un buen estudiante, el maestro que enseña bien ese concepto es un buen maestro; pero el maestro que enseña que debemos y tenemos la capacidad de transformar el mundo para mejorarlo es un maestro que trasciende.

Maestros como el doctor De la Isla dejan huellas imborrables en sus discípulos. La vida del alumno cambia radicalmente al pasar por un curso con un maestro de esa trascendencia. Ya no podemos decir "yo no sabía que el mundo era tan injusto"; no podemos decir tampoco: "nadie me dijo que yo podía contribuir a transformar el mundo". No tenemos ya la posibilidad de mostrar indiferencia. El maestro De la Isla dejó y sigue dejando una huella indeleble en sus alumnos; casi todos ellos tenemos pedazos, tirones, trozos de Carlos de la Isla en nuestras bolsas y en nuestros escritorios; a veces a la vista, a veces en el fondo, pero siempre se hacen presentes.

Lo anterior no quiere decir que todos sus alumnos seamos paladines eternos de la justicia y transformadores sociales perpetuos. Algunos tenemos caracteres diferentes, metas diferentes y, sobre todo, libre albedrío, lo cual entraña que si bien sabemos que tenemos la posibilidad de transformar nuestra realidad, habrá quienes optemos por no hacerlo. Aunque esta sea nuestra decisión, las reflexiones de aquellas clases siguen vigentes. 
Posiblemente si tomáramos como prototipo a otro maestro llegaríamos a conclusiones diferentes o complementarias. Sin embargo, analizando la vida docente del maestro De la Isla sabemos que el maestro que trasciende y que imprime su huella en el estudiante, lo hace cuando este tiene la posibilidad de cambiar sus ideas, su actitud, sus convicciones, sus compromisos y su visión del mundo. La calidad del maestro, por tanto, se puede medir no por la cantidad de alumnos que pasan por las aulas ni por la calidad que muestren en el desempeño de sus funciones, sino por el potencial de cambio que el maestro imprime en sus estudiantes.

Tal vez no podamos hallar fácilmente dicha característica, lo cual deja nuestra pregunta inicial sin una respuesta satisfactoria. Pero ante el ejemplo intachable del doctor De la Isla, de lo que sí podemos estar seguros es de que la obra diaria, callada, continua, reservada, humilde, tenaz y modesta de los maestros excepcionales puede trascender las aulas, transformar el mundo e intervenir directamente para lograr que este país sea un poquito menos injusto.

\section{C.P. Agustín Irurita Pérez}

Como exalumno del Instituto, es un gusto participar en este acto en honor del doctor Carlos de la Isla. Estudié la carrera de Contador Público de 1959 a 1963 y reconozco que en aquella época la formación humanística era escasa. Si bien la preparación en lo técnico era buena, los problemas a que pronto hice frente en la empresa fueron de otra índole: rechazo social a la función empresarial, corrientes ideológicas en pugna por el poder, estructuras políticas producto de un régimen centralista, paradigmas impuestos que marcaban la manera de ser de la sociedad y problemas humanos de convivencia.

¿Adónde recurrir para encontrar respuesta a estos problemas que eran diferentes? A base de preguntar, leer, participar en organismos intermedios, llegué a un curso de formación social de la Unión Social de Empresarios de México, donde conocí al doctor Carlos de la Isla. Él despertó en mí la inquietud por investigar más sobre estos temas y poner 
en práctica en la empresa los principios humanos y sociales que aprendí en su cátedra. Casi 30 años después, un hijo mío estudió aquí la misma carrera. Con alegría observé la importancia de la formación integral que ahora se imparte. Con sorpresa vi que el profesor más admirado de mi hijo y sus amigos era el doctor Carlos de la Isla. Sus conceptos, sus inquietudes, sus ideales forman parte muy importante del pensamiento de esta nueva generación.

La empresa es una institución fundamental de la sociedad moderna. Ver la realidad como es, entenderla y actuar con base en principios para servir a la sociedad es la primera responsabilidad del empresario. ¿Qué ocurre fuera? ¿Cómo funciona la sociedad? ¿Cuáles son sus paradigmas? ¿Qué queremos hacer? ¿Qué repercusión tiene lo que hacemos dentro y fuera de la empresa? ¿Hacia dónde nos dirigimos? Son preguntas que un empresario siempre debe procurar responder.

Cobra así un lugar fundamental la formación social, humana, ética y filosófica. Como bien dice y enseña el doctor De la Isla, en la empresa:

-El respeto a la dignidad de la persona determina la relación de convivencia con empleados y clientes.

-La solidaridad aglutina al grupo y le da cohesión, fuerza y fortaleza. -El desarrollo integral de la persona solo se alcanza de manera subsidiaria. Así, la asignación de responsabilidades junto con la autoridad posibilita que esta crezca.

-El desarrollo integral de la persona es una meta que se ha alcanzado cuando el cumplimiento de responsabilidades y el ejercicio de la autoridad van permeadas por la honestidad y el valor.

-La participación social en el logro de condiciones que permitan no solo el desarrollo de la empresa, sino de la sociedad en su conjunto (bien común), amplía el marco de acción del empresario.

Los anteriores son algunos de los principios que dan sentido y trascendencia a la función empresarial. Sin su aplicación, en la vida práctica se puede ganar dinero y ser una empresa o un empresario aparentemente exitoso; sin embargo, las desigualdades y problemas que se crean cuando dichos principios no se aplican, minan la convivencia justa y pacífica 
y dan al traste con lo creado. El doctor Carlos de la Isla ha dedicado su vida al estudio y a la investigación y enseñanza de lo social y lo humano. Posee una cultura y conocimientos muy amplios sobre estos temas y sabe transmitir con claridad y pasión sus conocimientos. Es un filósofo que con su testimonio personal da lugar al análisis, la discusión y la reflexión sobre diversas corrientes de pensamiento. Encarna sus convicciones, y esto constituye un ejemplo para todos. Apasionadamente, imparte enseñanzas a sus alumnos y crea en ellos una corriente de calidad humana que despierta lo mejor de cada uno. Ayuda con su pensamiento a que cada persona ubique los marcos de referencia que le servirán en la vida para comparar opciones y así tomar mejores decisiones. Cuestiona lo más profundo y ayuda a reordenar la estructura axiológica, tan importante en un mundo que hoy equipara el valor con el dinero. Y, lo más importante, ayuda a la formación de convicciones trascendentes que le dan estructura y sentido a la persona.

Doctor Carlos de la Isla:

Es para mí un honor dirigirme a usted en esta ocasión y reconocerle el enorme valor de su labor. Felicito al Instituto Tecnológico Autónomo de México por aquilatar la gran importancia que tiene en la educación la preparación social y humana y por el honor de tenerlo a usted como profesor. Quiero dar a usted las gracias a nombre de todos aquellos empresarios que lo hemos escuchado, por lo mucho que nos ha enseñado, motivado y comprometido.

Gracias mil y felicidades.

\section{Discurso del doctor Carlos de la Isla}

Señor Contador Público don Carlos Orozco, representante de la Junta de Gobierno del Instituto Tecnológico Autónomo de México;

Señor Rector Dr. don Arturo Fernández;

Señores miembros de las Juntas de Gobierno, de Coordinación y de la Facultad; 
Señoras y señores:

Muchas gracias.

Estoy profundamente emocionado y agradecido, pero al mismo tiempo me encuentro en esa situación angustiosa en la que el lenguaje no alcanza al sentimiento; y cuando la palabra no puede expresar el pensamiento es el momento de callar; es la zona del silencio.

Por otra parte, siento la necesidad de contar un breve relato que por la amabilidad de su interpretación cumplirá el objetivo que es mostrar mi experiencia agradecida.

¡Qué ironía de la vida académica! Yo que soy fuertemente alérgico a los homenajes y a las solemnidades, siento que se descarga sobre mi fragilidad todo el peso de esta gran celebración.

Sin embargo, pronto me libero de tal carga cuando percibo el verdadero significado de esta fiesta poco usual; y desde tal perspectiva el yo personal se desvanece y toman cuerpo dos virtudes genuinamente universitarias que, ellas sí, merecen todas las aclamaciones: la honra de la universidad y la dignidad del magisterio; una universidad se honra cuando honra a sus maestros. En la calidad de sus maestros está custodiado el tesoro de su autonomía, de su libertad, de su masa crítica, de su actividad creadora, de su producción intelectual, de su formación humana transformadora de la sociedad.

Por eso don Raúl Baillères tuvo muy lúcida intuición cuando hace poco más de 50 años, preocupado por los graves problemas de México, al pensar en sus posibles soluciones, fundó el ITAM. Percibió que la única verdadera solución a los problemas más dolorosos en los ámbitos social, político y económico es una educación de calidad. Y tenía razón. Don Alberto heredó esa misma convicción, por eso con frecuencia afirma que en el ITAM están puestas sus preferencias y sus esperanzas. Hay que señalar que lo demuestra en su incondicional apoyo, y principalmente en su respeto a la autonomía, a la libertad académica, a las labores formativas en favor de una educación crítica, creativa y responsable. Y allí, en esa dirección, sigue estando la esperanza de México.

Considerada esta gran celebración como un formal y merecido homenaje a la honra de la universidad y a la dignidad del magisterio, acepto gozoso el peso de tanta solemnidad. 
Hace casi 30 años, cuando fui invitado por el profesor José Ramón Benito a colaborar en las tareas docentes del distinguido Departamento de Estudios Generales del ITAM, confieso que me sentí fuertemente atraído por sus objetivos y su filosofía educativa, comprometidos con el desarrollo integral de las personas, con la defensa de sus derechos que derivan de su dignidad, de su libertad, de su igualdad. Excelente propósito, porque a eso se reduce el ideal de la educación que tantas veces es olvidado y hasta agredido, cuando se viola la dignidad de la persona para convertirla en un medio del proceso productivo.

Ese fue el ideal genuino del entonces reciente movimiento del 68, en el que muchos estudiantes y profesores luchamos con convicción por una universidad que no fuera o no se convirtiera en vulgar maquiladora de productos humanos demandados en el mercado de las profesiones; por una universidad libre, defensora de la libertad con la fuerza de la verdad; por una universidad dedicada a pensar y a proteger la dignidad de las personas; por una universidad constructora de utopías frente al realismo inhumano predominante; por una universidad que, como conciencia crítica de la sociedad, estuviera comprometida con los graves problemas sociales, pero desde la autonomía del pensamiento y de la acción; por una universidad que no fuera la torre de marfil de los privilegiados, pero tampoco un mero apéndice de los poderes políticos y económicos; por una universidad que fuera luz y proyectara luz sobre tantas oscuridades, generadora del saber dirigido al quehacer humanizante.

En sus objetivos, el ITAM se compromete a luchar por una sociedad más libre, más justa, más humana. Es decir, se compromete a intentar el cambio de esta sociedad globalizante que también ha globalizado la arbitrariedad, el abuso de los pocos poderosos sobre los muchos débiles, el valor del dinero sobre el de las personas, el cinismo del poder que coloca junto a millones de armas, millones de hambrientos; sociedad esta de la paradoja perversa: de los medios maravillosos para ordenar al mundo y del desorden del mundo por el frecuente uso destructivo de los medios. 
Este compromiso con la transformación de la sociedad entraña plantearse toda una cosmovisión educativa coherente. Por eso en su filosofía el ITAM rechaza la educación receptiva, acrítica, dogmática, profética, utilitarista, gregaria y reproductora, y se propone una educación entendida como servicio al desarrollo personal en todas sus dimensiones, una educación que se justifica en la persona misma, que fomenta la afirmación del pensamiento crítico, de la imaginación, de la creatividad, el crecimiento del estudiante que piensa en una universidad que piensa y se piensa críticamente, que juzga y que construye modelos inspiradores de una realidad distinta. Porque solo estudiantes que piensan en serio, con capacidad de juzgar, de descubrir, de inventar, de crear; estudiantes que no se enclaustran en el pobre recinto de sus intereses individualistas, sino que tienen la sensibilidad para condolerse por el abuso del poder y la injusticia; solo tales estudiantes con dicha educación serán capaces de crear utopías y de comprometerse con su construcción. Debo decir que he conocido un buen número de estos estudiantes en el ITAM.

De aquí la coherencia entre fines sociales y medios educacionales que me atrajeron fuertemente. Y si hace 30 años estos objetivos tenían vigencia y urgencia, hoy, al final del milenio, son más urgentes aún. Ahora es más imperativo el compromiso con una sociedad mucho más libre, mucho más justa, mucho más humana; y por tanto, resulta más necesaria la educación para la libertad y la creatividad.

El logro de tales metas sería una quimera sin el absoluto respeto a la libertad de cátedra, que constituye no solo el sostén, sino la generación misma de la esencia de la universidad. ¿Cómo puede ser concebida la universalidad sin la libertad que define la esencia misma de la universidad? ¿Cómo podría concebirse la pluralidad del pensamiento filosófico, el desarrollo científico, las invenciones, las creaciones y la riqueza de la cultura sin la libertad para disentir, para cuestionar, para objetar o aprobar? Lo más aproximado a la certidumbre en las cercanías de la verdad es resultado de la resistencia a la masa crítica que es la descarga de la libertad.

Así como la historia de la humanidad ha sido la lucha del avance de la libertad sobre las dominaciones y esclavitudes, así como la vida del 
ser humano es la lucha de la libertad que quiere ganarle campo a la inevitabilidad, así también las grandes avanzadas de la universidad sobre las imposiciones ideológicas, sobre las oscuridades y sobre las agresiones de los poderes, han sido triunfos de la libertad. Por eso la universidad debe defender la libertad como a su más valioso tesoro, sobre todo ahora que las fuerzas mercantiles y políticas parecen irresistibles. Una universidad sin libertad no pasa de ser una academia de partido, desvertebrada.

Yo no puedo juzgar sobre el grado en que el ITAM ha cumplido sus objetivos sociales y educacionales; tal vez solo el tiempo y la historia lo dirán. Lo que sí puedo afirmar con la certeza de mi experiencia es que mi libertad de expresión en la cátedra ha sido irrestricta, intocada a pesar de mi actitud permanentemente crítica y con frecuencia disidente. Y esta es una virtud inconmensurable que alabo y agradezco profundamente; estoy seguro de que cualquier logro de cualquier tamaño del ITAM se ha gestado en proporción al respeto brindado a la libertad. Por supuesto que mi apreciación se extiende al campo exclusivo de mi experiencia.

Sobre esta distinción que se me otorga, debo decir que si el mérito del profesor emérito significa completud y plenitud en el desempeño de mi oficio académico, estoy muy lejos de merecerla. Pero si ese mérito contempla la devoción al pensamiento, cierta fe y pasión por la verdad, un amor respetuoso a los alumnos, un esfuerzo de mostración sincera de que existe lo fugaz pero también lo permanente en la permanencia de esos bienes también llamados "amores" o "valores" por los que vale mucho la pena vivir la vida, y la comunicación del coraje por la inequidad del mundo que puede evitarse; si se llama mérito a estas y otras cuestiones por el estilo, debo decir que estaría rondando las mieses cercanas a ese fruto.

Aunque, hablando de gratificación al mérito, pienso que la gran recompensa la encuentra un profesor en su propio oficio, que no es de modelador, ni de profeta, ni de guía ni de guardián del dogma (concepciones soberbias, falsas y pobres del maestro). El oficio del maestro no es solo, como decía Sócrates, el del partero en cuanto auxilia el parto de 
las almas; porque todo hombre vive de ideas, el maestro que colabora en la gestación de las ideas colabora también en la hechura de la existencia, y con frecuencia el poder de las ideas ocupa mayor dimensión en el ámbito de la personalidad que las mismas imposiciones genéticas. El maestro que auxilia en la iluminación de la verdad genera libertad, porque la verdad hace libres a los hombres. ¿Qué mejor profesión y mayor recompensa que la modesta pero importantísima colaboración en la hechura de la vida y de una vida de posible libertad tal vez para muchos estudiantes?

Sin embargo, un aspecto muy satisfactorio de esta distinción que se me hace es que la universidad que me distingue resulta más distinguida por otorgar dicha distinción, porque en la sociedad es muy común aplaudir a quienes aprueban, premiar a los que halagan; pero hacer un reconocimiento de mérito a quien ha mantenido una actitud crítica significa respeto y exaltación a la pluralidad necesaria, a la disidencia fundada, al cuestionamiento honrado. Y qué bueno, porque las grandes universidades han construido su grandeza con la argamasa del cuestionamiento, que es la salud del pensamiento.

La filosofía, la ciencia, la técnica y lo mejor de la cultura humana no son resultado de la aprobación, del triunfalismo, del aplauso, sino de la permanente actitud crítica, porque la crítica es la gran depuradora de la verdad que, como la libertad, se hace día a día.

Por ello principalmente me honra esta distinción. No voy a singularizar mi agradecimiento, porque tardaría muchas horas y porque toda elección significa una indeseable exclusión. Solo un especial reconocimiento al muy importante y distinguido Departamento de Estudios Generales en el que he desarrollado mi modesta actividad educativa. Agradezco a todos y a cada uno de los integrantes del ITAM con los que he convivido estos casi 30 años de vida académica, porque su compañía y su bondad han hecho posible este magisterio de la educación, este magisterio de la libertad que es el ministerio de la razón en busca de la verdad que une a los hombres y debe construir un México mucho mejor.

Gracias por esta distinción que honra al ITAM, que honra a mi familia y que gustosamente comparto con todos ustedes. ¡Muchas gracias! 